\title{
The gains from cooperative R\&D with a concave technology and spillovers ${ }^{1}$
}

\author{
Luca Lambertini $^{\S} \# 2$ - Gianpaolo Rossini ${ }^{\S 3}$ \\ $\S$ Department of Economics, University of Bologna \\ Strada Maggiore, 45, I-40125 Bologna, Italy \\ Fax ++39.051 .2092664$ \\ \# ENCORE, Faculty of Economics \& Econometrics \\ University of Amsterdam, Roetersstraat 11 \\ 1018 WB Amsterdam, The Netherlands
}

May 27, 2004

\footnotetext{
${ }^{1}$ We thank Cristian Dezso and the audience at IIOC 2004 (Chicago, April 2324, 2004), for helpful comments and discussion. The usual disclaimer applies. We acknowledge the financial support of the University of Bologna under the $60 \%$ scheme for the year 2003 and the financial support of the Italian Ministry of Education within the $40 \%$ scheme for the year 2004 .

${ }^{2} \mathrm{Ph} .++39.051 .2092623$, lamberti@spbo.unibo.it

${ }^{3} \mathrm{Ph} .++39.051 .2092607$, rossini@spbo.unibo.it
} 


\begin{abstract}
We reassess the respective gains from $R \& D$ cooperation and competition in a Cournot Duopoly with homogeneous goods, where firms adopt a concave cost-reducing R\&D technology. Contrary to the previous literature on the same topic, our main results are that (i) no corner solutions emerge and (ii) cooperation, in the form of either a cartel or a joint venture, is always profitable for firms and (iii) socially superior to independent ventures, provided that spillovers are sufficiently high.
\end{abstract}

JEL Classification: L13, O31

Keywords: process innovation, $R \& D$ cooperation, joint ventures 


\section{Introduction}

The National Research Cooperation Act (1984) fosters R\&D cooperation as a remedy to the well known effort duplication drawback affecting R\&D races. ${ }^{1}$ The existence of substantial spillovers in the R\&D activity, as evidenced in Jaffe (1986), has added momentum to the justification of a benevolent stance towards cooperation in research. Following Katz (1986), a large body of literature has built the theoretical foundations and the policy legitimation to such measures. The most relevant contributions concerning the desirability of R\&D cooperation are d'Aspremont and Jacquemin (1988), Kamien et al. (1992), Suzumura (1992) and Amir (2000), to mention only a few. A thorough assessment can be found in Katz and Ordover (1990).

d'Aspremont and Jacquemin (1988) examine a Cournot duopoly, where each firm enjoys a spillover from the rival in terms of the final outcome of $\mathrm{R} \& \mathrm{D}$ activity, in the following sense. To firm $i$, investing $k_{i} \operatorname{costs} b k_{i}^{2}$ (i.e., there are decreasing returns to $\mathrm{R} \& \mathrm{D})$, but effective $\mathrm{R} \& \mathrm{D}$, reducing firm $i$ 's marginal cost $c_{i}$, is $K_{i}=k_{i}+\beta k_{j}$, where $\beta \in[0,1]$ is the extent of the externality from the rival. Therefore, given a generic initial marginal cost $\bar{c}$, we have $c_{i}=\bar{c}-K_{i}$. In Kamien et al. (1992), instead, the spillover effect is measured in value terms. They assume that each firm has a concave R\&D technology $f\left(Y_{i}\right)$, where $Y_{i}=y_{i}+\beta y_{j}$ is the effective R\&D effort, while firm $i$ 's marginal cost is $c_{i}=\bar{c}-f\left(Y_{i}\right)$. This is coupled with linear R\&D costs equal to $y_{i}$. Using $f\left(Y_{i}\right)=\sqrt{y_{i}+\beta y_{j}}$, Amir (2000) shows that the two models are isomorphic up to the transformation $k_{i}=y_{i} / \sqrt{b}$. For this reason, one may restrict the focus simply upon d'Aspremont and Jacquemin (1988). They

\footnotetext{
${ }^{1} \mathrm{~A}$ similar view has been also adopted in the EU (EC commission, 1990) and Japan (see Goto and Wakasugi, 1988).
} 
compare two different games. In the first, firms behave noncooperatively in choosing both $R \& D$ efforts and output levels. In the second, firms set up a cartel in the $R \& D$ stage, tuning $R \& D$ investments so as to maximise joint profits only in that stage, while remaining Nash rivals in the market stage. From the comparison of the two setups, d'Aspremont and Jacquemin (1988) discover that, for large spillover levels $[\beta>1 / 2]$, (i) $R \& D$ investments - and cost reduction - are higher with cooperation, and conversely for small spillovers; (ii) social welfare is superior again under cooperative behaviour, and conversely. Unfortunately, a shortcoming emerges since profits turn out to be larger with cartel than with noncooperation when spillovers are low $[\beta<1 / 2]$. We are then left with an unpleasant conflict between private and social incentives towards R\&D cooperation (or cartel). Jaffe (1986)

A further drawback appears since the model of d'Aspremont and Jacquemin lacks an internal optimum over the whole admissible range of parameters. ${ }^{2}$

In this paper we address the same issue, i.e., the possible gains from $\mathrm{R} \& \mathrm{D}$ cooperation as compared to competition. We design a concave $\mathrm{R} \& \mathrm{D}$ technology with linear costs, such that (i) no corner solution emerges and (ii) cooperation, in the form of either a cartel or a joint venture, is profitable for firms irrespective of the level of spillovers and also (iii) socially beneficial vis à vis independent ventures, when technological spillovers are sufficiently large. This result shows up even though we keep unaltered the conditions on demand and production costs embraced in the aforementioned literature. Moreover, it appears to be in line with empirical research assessing the size of technological spillovers (Jaffe, 1986).

The remainder of the paper is structured as follows. The basic setup is

\footnotetext{
${ }^{2}$ On this point, see Henriques (1990), d'Aspremont and Jacquemin (1990) and Amir and Wooders (1998).
} 
laid out in section 2. Sections 3, 4 and 5 examine the cases of noncooperative $R \& D$, the R\&D cartel and the joint venture, respectively. Private and social incentives towards $R \& D$ cooperation are evaluated in section 6 . Section 7 contains concluding remarks.

\section{The model}

Consider a Cournot duopoly with homogeneous products where the demand function is

$$
p=a-q_{1}-q_{2}
$$

and firm $i$ operates with the following cost function

$$
C_{i}=c_{i} q_{i}+r k_{i}
$$

where $r$ is the rental price of capital and $k_{i}$ is the capital commitment devoted to process innovation. The linear cost associated with the R\&D effort fits situations where firms must raise funds $k_{i}$ in order to finance research activities, at the cost measured by the relevant interest rate on long-run investments determined on capital markets. I.e., $r k_{i}$ is indeed the opportunity cost of committing resources $k_{i}$ to $\mathrm{R} \& \mathrm{D}$ instead of investing them otherwise. If each firm activates an independent research division, the $R \& D$ technology is described by:

$$
c_{i}=\bar{c}\left(1-\frac{k_{i}+\beta k_{j}}{1+k_{i}+\beta k_{j}}\right),
$$

where $\beta \in[0,1]$ measures the reciprocal technological spillover received from the other firm. ${ }^{3}$ This R\&D technology is concave and bounded above and

\footnotetext{
${ }^{3}$ Here, as in d'Aspremont and Jacquemin (1988) and the majority of the existing literature on these issues, the spillover level is exogenous and symmetric across firms. The
} 
below. In particular,

$$
\begin{gathered}
c_{i}=\bar{c} \text { iff } k_{i}=k_{j}=0 \\
\lim _{k_{i} \rightarrow \infty} c_{i}=0 .
\end{gathered}
$$

If firms jointly activate a single $\mathrm{R} \& \mathrm{D}$ lab, production technology will be the same for both firms, i.e.: $c_{i}=c_{j}=c$. Undertaking an RJV involves $i$ ) the sharing of $\mathrm{R} \& \mathrm{D}$ costs, i.e.: $\left.k_{i}=k / 2 ; i i\right) \beta=1$. Therefore, $\mathrm{R} \& \mathrm{D}$ technology becomes:

$$
c=\bar{c}\left(1-\frac{k}{1+k}\right) .
$$

Considered together, the cost function (2) and the R\&D technology (3) or (5) replace the linear technology and the convex R\&D cost function previously considered in d'Aspremont and Jacquemin (1988). It is also worth noting that the present setup cannot be transformed into theirs, as it was instead the case with the approach adopted by Kamien et al. (1992). This is due to the fact that here (either in (3) or in (5)) c goes to zero only in the limit, as the industry R\&D effort becomes infinitely large.

Regardless of the organization of the research activity, in the market stage firms always adopt a Cournot stance. Accordingly, individual equilibrium output is:

$$
q_{i}^{*}=\frac{a-2 c_{i}+c_{j}}{3},
$$

so that the profit function of firm $i$ at the first stage of the game is:

$$
\pi_{i}=\frac{\left(a-2 c_{i}+c_{j}\right)^{2}}{9}-r k_{i} .
$$

endogenisation of spillovers is investigated in Katsoulacos and Ulph (1998) and Amir and Wooders (2003). 


\section{Noncooperative $R \& D$}

Here, we assume that firms behave noncooperatively in the first stage. The first order condition (FOC), for firm $i$, is:

$$
\begin{aligned}
& \frac{\partial \pi_{i}}{\partial k_{i}}=\frac{2 \bar{c}}{9}\left[a-\bar{c} \frac{\left(1+k_{i}(2 \beta-1)+k_{j}(2-\beta)\right)}{\left(1+k_{i}+\beta k_{j}\right)\left(1+k_{j}+\beta k_{i}\right)}\right] . \\
& \cdot\left[\frac{2\left(1+k_{j}+\beta k_{i}\right)^{2}-\beta\left(1+k_{i}+\beta k_{j}\right)^{2}}{\left(1+k_{i}+\beta k_{j}\right)^{2}\left(1+k_{j}+\beta k_{i}\right)^{2}}\right]-r=0
\end{aligned}
$$

which, imposing the symmetry condition $k_{j}=k_{i}$, becomes ${ }^{4}$ :

$$
\frac{\partial \pi_{i}}{\partial k_{i}}=\frac{2 \bar{c}(2-\beta)\left[a\left(1+k_{i}(1+\beta)\right)-1\right]-9 r\left(1+k_{i}(1+\beta)\right)^{3}}{9\left(1+k_{i}(1+\beta)\right)^{3}}=0 .
$$

The Nash equilibrium R\&D effort is:

$$
k^{N}=\frac{6 \operatorname{ar} \bar{c}(2-\beta)(1+\beta)^{4}-9 r(1+\beta)^{2} \quad \sqrt[3]{3 \Phi}+\sqrt[3]{9 \Phi^{2}}}{9 r(1+\beta)^{3} \sqrt[3]{3 \Phi}}
$$

where

$$
\Phi=(2-\beta)(1+\beta)^{6}\left[\sqrt{3 \bar{c}^{3} r^{3}\left[243 \bar{c} r-8 a^{3}(2-\beta)\right]}-27 \bar{c}^{2} r^{2}\right] .
$$

Non negativity and reality conditions require that:

$$
r \geq \frac{8 a^{3}(2-\beta)}{243 \bar{c}}=r^{N}
$$

We are then able to state the following:

Proposition 1 For all $r \geq r^{N}$ we have a unique interior equilibrium for the $R ध D$ stage where $k_{i}=k^{N}$ for $i=1,2$.

\footnotetext{
${ }^{4}$ The equation has 3 roots, out of which only one is real.
} 
Proof. See Appendix.

By iterating the Hôspital rule we get:

$$
\lim _{r \rightarrow \infty} k^{N}=0
$$

Moreover, $k^{N}$ is always decreasing in $r$.

Using $k^{N}$, one can obtain industry profits and social welfare at the Nash equilibrium. Consumer surplus is defined as:

$$
C S^{N}=\frac{\left(a-p^{N}\right)\left(q_{1}^{N}+q_{2}^{N}\right)}{2} .
$$

Therefore, welfare is $S W^{N}=C S^{N}+\sum \pi_{i}^{N} \cdot{ }^{5}$

\section{$4 \quad \mathrm{R} \& \mathrm{D}$ cartel}

When firms build up a cartel in the R\&D stage, they choose R\&D efforts so as to maximize joint profits. Accordingly, their objective, in the first stage, becomes:

$$
\max _{k_{i}, k_{j}} \Pi^{C}=\sum \pi_{i}=\sum\left[\frac{\left(a-2 c_{i}+c_{j}\right)^{2}}{9}-r k_{i}\right] .
$$

The distinctive feature of cartel behaviour consists in internalising the spillover effect. This can be seen by writing the FOC as follows:

$$
\frac{\partial \Pi^{C}}{\partial k_{i}}=\frac{\partial \pi_{i}}{\partial k_{i}}+\frac{\partial \pi_{j}}{\partial k_{i}}=0
$$

The solution is ${ }^{6}$ :

$$
k^{C}=\frac{6 a r \bar{c}(1+\beta)^{5}-9 r(1+\beta)^{2} \sqrt[3]{3 \Psi}+\sqrt[3]{9 \Psi^{2}}}{9 r(1+\beta)^{3} \sqrt[3]{3 \Psi}}
$$

\footnotetext{
${ }^{5}$ Throughout the paper, the expression of consumer surplus and social welfare are omitted for brevity. They are availble upon request.

${ }^{6} \mathrm{As}$ in the fully noncooperative case the FOC yields 3 solutions, out of which only one is acceptable.
} 
where

$$
\Psi=r \bar{c}(1+\beta)^{7}\left[\sqrt{3 \bar{c} r\left[243 \bar{c} r-8 a^{3}(1+\beta)\right]}-27 \bar{c} r\right] .
$$

Non negativity and reality conditions require that:

$$
r \geq \frac{8 a^{3}(1+\beta)}{243 \bar{c}}=r^{C} .
$$

It can be verified that $r^{N} \geq r^{C}$ for $\beta \in[0,1 / 2]$ and conversely in the remainder of the admissible interval of the spillover parameter.

Therefore:

Proposition 2 For all $r \geq r^{C}$ we have a unique interior equilibrium for the $R \& D$ stage where $k_{i}=k^{C}$ for $i=1,2$.

Proof. The proof is omitted as it replicates the same procedure seen in Proposition 1.

As in the fully noncooperative setting, the optimal R\&D effort is everywhere decreasing in $r$, shrinking to zero in the limit when the cost of capital becomes infinitely high. Using the equilibrium controls we can get the optimal profits and social welfare as in the previous section.

\section{RJV}

Alternatively, firms may undertake joint $R \& D(R J V)$. As a result $R \& D$ is carried out in a single lab jointly funded by both firms symmetrically sharing the cost. Accordingly, the objective of the single firm is:

$$
\begin{aligned}
\max _{k} \pi & =\frac{(a-c)^{2}}{9}-\frac{r k}{2} \\
\text { s.t. } & : \quad c=\bar{c}\left(1-\frac{k}{1+k}\right)
\end{aligned}
$$


Owing to the RJV, we impose (i) symmetry on marginal costs and R\&D efforts across firms, and (ii), full spillovers, i.e., $\beta=1$. Then the FOC is:

$$
\frac{\partial \pi}{\partial k}=\frac{4 \bar{c}[a(1+k)-\bar{c}]-9 r(1+k)^{3}}{18(1+k)^{3}}=0 .
$$

The only admissible solution is:

$$
k^{R J V}=\frac{2 a r \bar{c}^{3} \sqrt{36}-9 r^{3} \sqrt{\Omega}+\sqrt[3]{6 \Omega^{2}}}{9 r^{3} \sqrt{\Omega}}
$$

where

$$
\Omega=r \bar{c}\left[\sqrt{3 \bar{c} r\left[243 \bar{c} r-16 a^{3}\right]}-27 \bar{c} r\right] .
$$

Reality and non negativity conditions require that

$$
r \geq \frac{16 a^{3}}{243 \bar{c}}=r^{R J V}
$$

This is the most restrictive condition met so far.

Therefore:

Proposition 3 For all $r \geq r^{R J V}$ we have a unique interior equilibrium for the RED stage where $k=k^{R J V}$.

Proof. The proof is omitted as it parallels that of Proposition 1.

As in the previous cases, the optimal R\&D effort is everywhere decreasing in $r$, shrinking to zero in the limit when the cost of capital becomes infinitely high. Equilibrium values of sales and $R \& D$ investments can be used to obtain the optimal profits and social welfare.

\section{Private and social incentive to $R \& D$ coop- eration}

Thanks to the equilibrium expressions of $k^{N}, k^{C}$ and $k^{R J V}$, we can deliver the corresponding profits, consumer surplus and social welfare in the three 
alternative settings. It turns out that, irrespective of the values of parameters $\{a, \bar{c}, r\}$, private and social preferences concerning the organizational design of R\&D activity depend, in general, upon the level of the technological spillover $\beta$. The qualitative aspects of such preferences, concerning the individual firm's profits, consumer surplus and social welfare, are displayed in figures 1-3.

Consider figure 1. The difference $\pi^{C}-\pi^{N}$ (figure 1a) is positive for all admissible values of $\beta$, except $\beta=1 / 2$ where noncooperative profits equal cartel profits. This is due to the fact that in correspondence of $\beta=1 / 2$ the beneficial externality that a firm receives from the rival at the Nash equilibrium of the noncooperative $R \& D$ stage is exactly equivalent to internalising the same externality in a cartel. Figure $1 \mathrm{~b}$ portrays $\pi^{R J V}-\pi^{N}$, which is always positive as firms share the cost of a single R\&D lab, but intuitively decreasing in $\beta$ since increasing the spillover makes joint investment, although always convenient, progressively less so as compared to independent ventures. Figure 1c draws $\pi^{R J V}-\pi^{C}$; here, the previous argument goes through largely unchanged, although of course $\pi^{R J V}=\pi^{C}$ in $\beta=1$, since full spillovers make firms just indifferent between cost sharing and joint profit maximisation.

Now examine figure 2. From figure 2a, observe that $C S^{C}>C S^{N}$ for all $\beta \in(1 / 2,1]$, and conversely in the remainder of the parameter interval. This is a consequence of the balance between the beneficial effects of internalising spillovers by means of R\&D cartelisation, and the damage that joint profit maximisation at the first stage necessarily entails. As for figures $2 \mathrm{~b}$ and $2 \mathrm{c}$, here we have that $C S^{R J V}>C S^{N}$ and $C S^{R J V}>C S^{C}$ always, with cartel and joint venture performing equally well at $\beta=1$.

Figure 3 summarises all of the above effects in terms of social welfare. In particular, $S W^{C}>S W^{N}$ for all $\beta \in(1 / 2,1]$ as a consequence of the 
behaviour of consumer surplus in the same parameter subset. Again, under full spillovers, the performance of an R\&D cartel exactly replicates that of an RJV.

Figure 1a

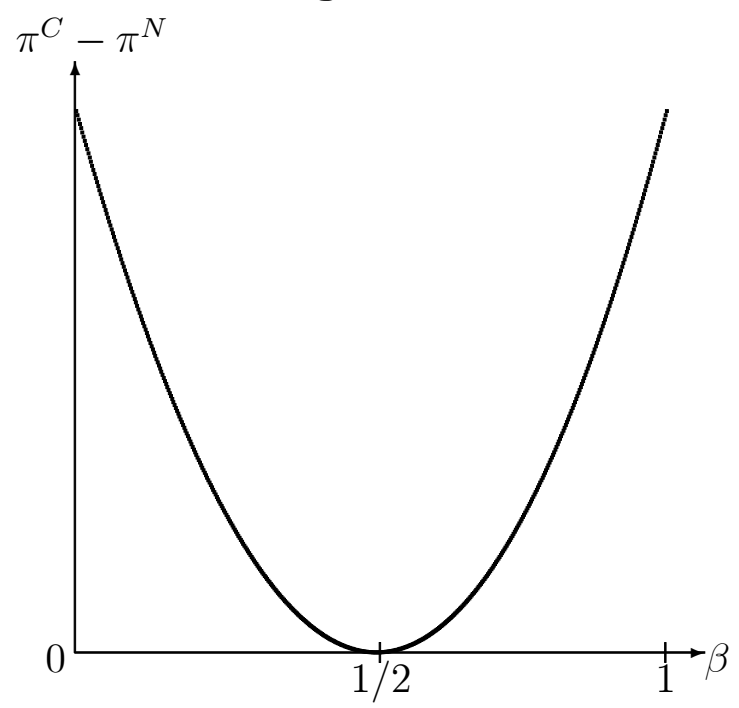

Figure 1b

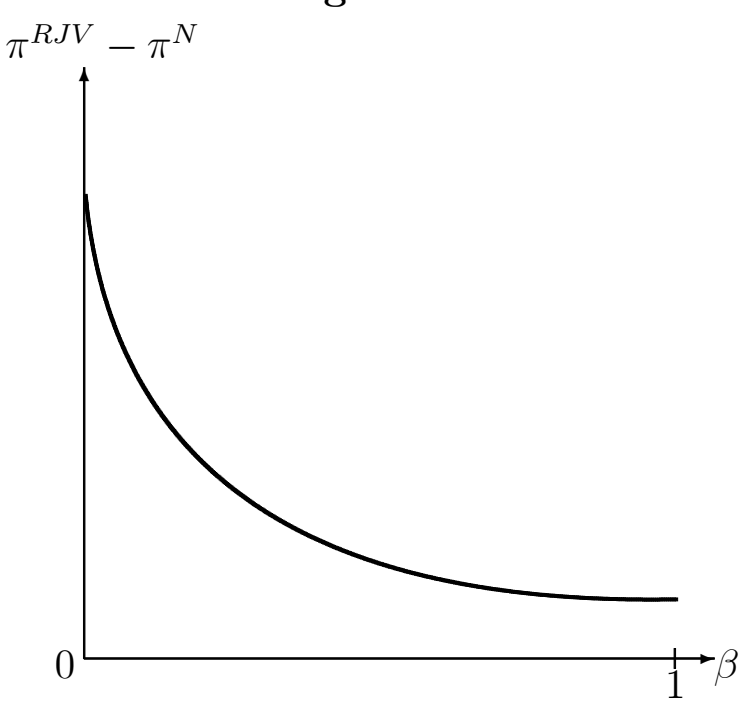

Figure 1c

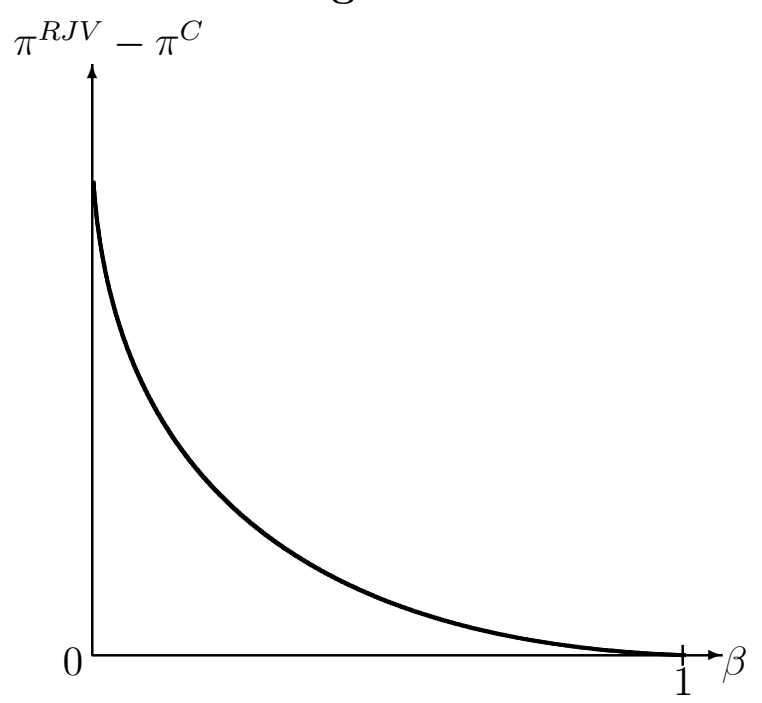


Figure 2a

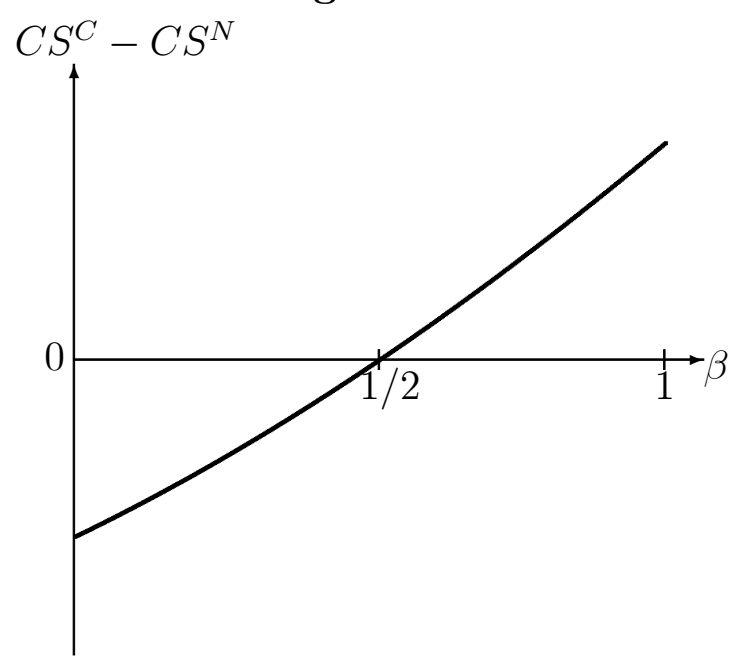

Figure 2b

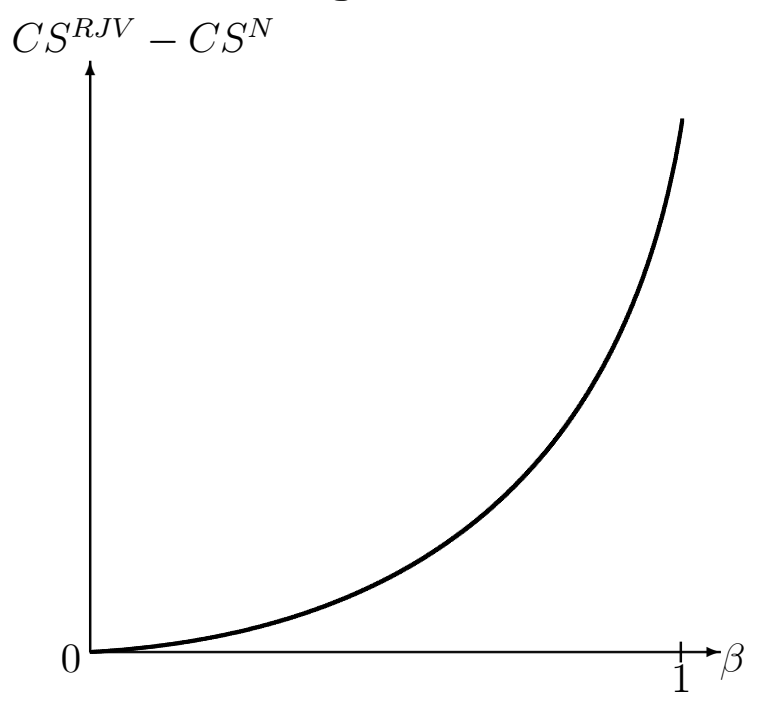

Figure 2c

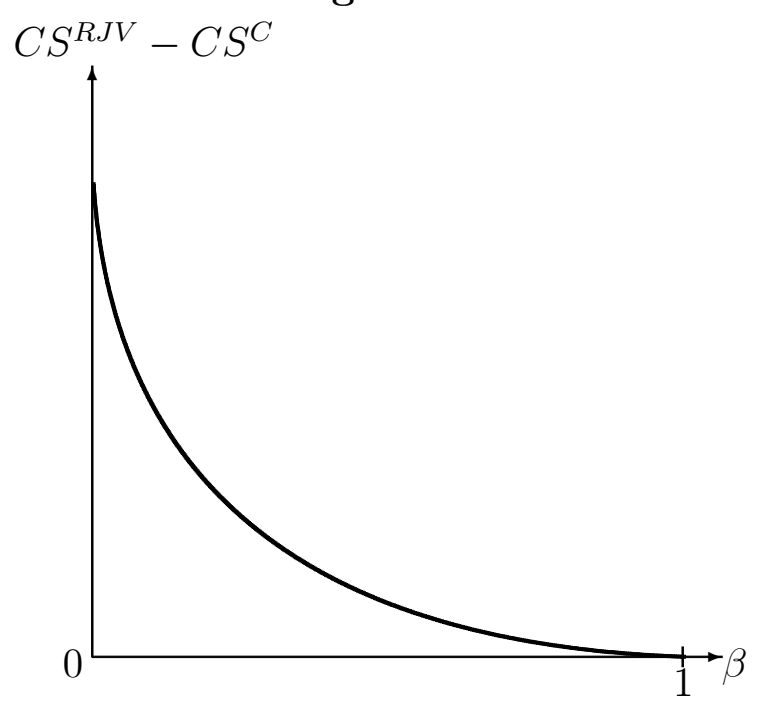


Figure 3a

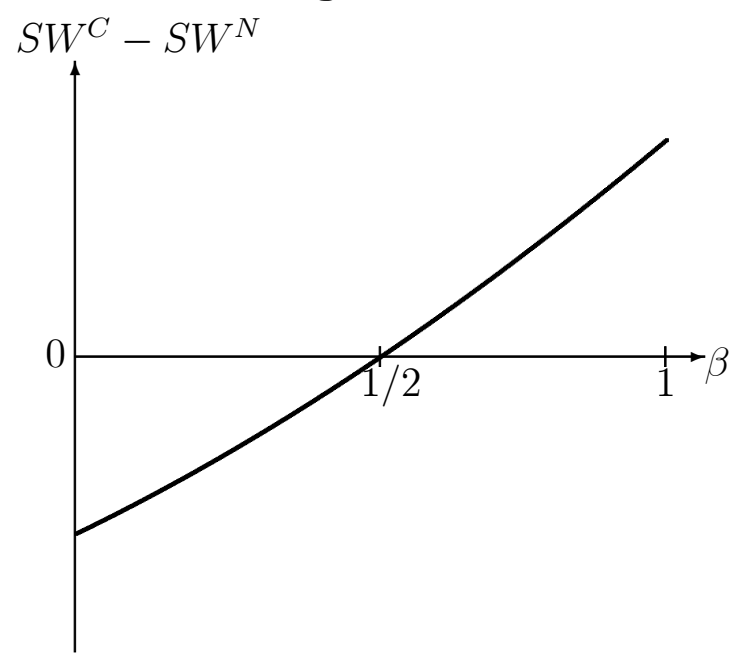

Figure 3b

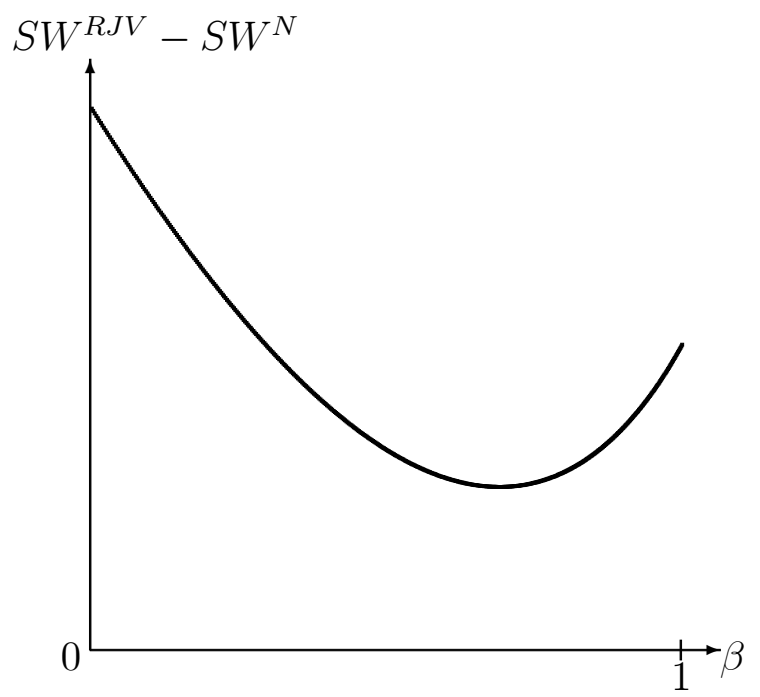

Figure 3c

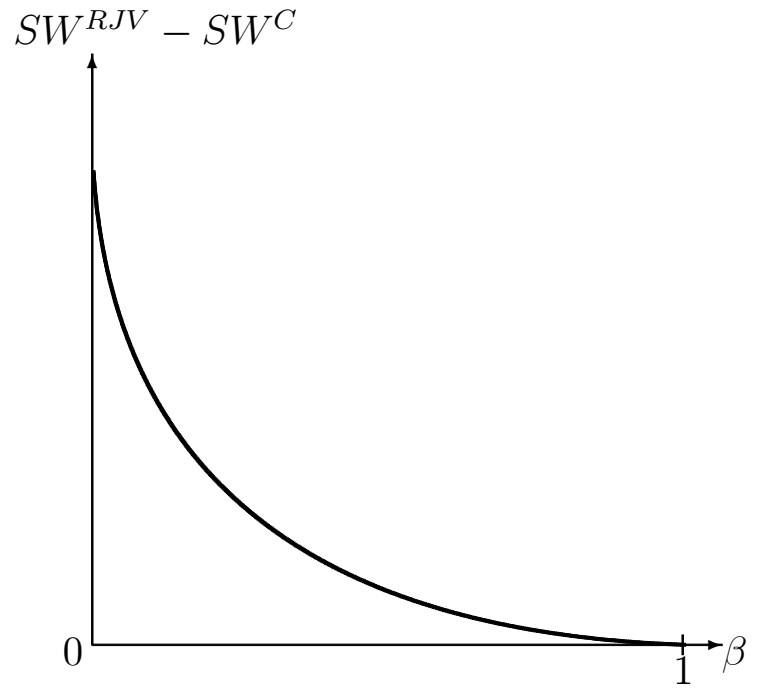

From the comparison of the three scenarios investigated above, we can draw the following conclusions:

Proposition 4 (Private incentives) $\pi^{R J V}>\pi^{C}>\pi^{N}$ for all admissible spillover levels. 
More precisely: the higher is the intensity of cooperation in the $R \& D$ stage, the higher are the profits accruing to firms in equilibrium. Note that the turning point $\beta=1 / 2$, around which the incentives to cooperate or compete used to flip over in the previous approach (d'Aspremont and Jacquemin, 1988) has now disappeared. The above proposition is intuitive if one recognizes that firms evaluate the option to activate some form of $R \& D$ cooperation against the alternative of undertaking independent ventures, all else equal. In the market stage firms compete à la Cournot-Nash, no matter what they have previously chosen as to the design of $R \& D$ activity. That is, an R\&D cartel must always be preferred to Nash behaviour, because firms maximise joint profits at the first stage. This holds, a fortiori, if they establish a research joint venture, reaping further cost savings.

Proposition 5 (Social incentives) $S W^{R J V}>S W^{N}>S W^{C}$ for all $\beta \in$ $[0,1 / 2) ; S W^{R J V}>S W^{C}>S W^{N}$ for all $\beta \in(1 / 2,1]$.

The above Proposition says that, in general, the RJV with $\beta=1$ welfaredominates the alternative $R \& D$ arrangements. As in the linear technology case investigated by d'Aspremont and Jacquemin (1988), R\&D cooperation in the form of a cartel is socially efficient if and only if spillovers are large enough, and conversely. If $\beta$ is large, cooperation internalises the benefits generated by $R \& D$ efforts largely enough to justify $R \& D$ cartelisation from the social standpoint. Leaving aside RJVs, this discussion leads to the following Corollary:

Corollary 1 For all $\beta \in(1 / 2,1]$, both private and social incentives point to the adoption of a cartel in the REDD stage, if the alternative is competition.

The above corollary is the main result drawn from the foregoing analysis. It states that if technological externalities are large enough, then R\&D co- 
operation is both profitable and socially efficient, in sharp contrast with the previous literature on the same topic.

Finally, taking into account the possibility of setting up RJVs, Propositions 4-5 also entail the following:

Corollary $2 R J V$ is profit - and welfare - superior as compared to both competitive and cartel RED, irrespective of the level of spillovers.

Intuitively, the private and social desirability of a research joint venture vis à vis any alternative organisational design of $\mathrm{R} \& \mathrm{D}$ activities stems from the saving effect implicit in activating a single research lab, whose costs are shared by firms. This enhances profits as well as social welfare.

\section{Concluding remarks}

We have revisited the issue of cooperative $R \& D$ investments in a Cournot duopoly where the R\&D technology is characterised by spillovers and it is immune from corner solutions at the $R \& D$ stage of the game. In our fresh framework the conflict between private and social incentives towards R\&D cooperation, highlighted in previous contributions, may disappear. ${ }^{7}$ In particular, R\&D cartelisation is privately and socially preferable to R\&D competition if spillovers are large enough, which is the most common case, as empirical research on this issue confirms (see, e.g., Jaffe, 1986). RJV remains the best alternative from both standpoints irrespective of the level of technological externalities.

\footnotetext{
${ }^{7}$ The analysis of a dynamic game where smoothing the R\&D investment plan over an arbitrarily long time horizon has similar consequences is in Cellini and Lambertini (2003).
} 


\section{Appendix}

Here we go through the SOCs to prove Proposition 1. Under the symmetry condition $k_{j}=k_{i}$, local optimality is assured by:

$$
\frac{\partial^{2} \pi_{i}}{\partial k_{i}^{2}}=-\frac{2 \bar{c}\left[\bar{c}(\beta(4+\beta)-8)+2 a\left(k_{i}(1+\beta)+1\right)\left(2-\beta^{2}\right)\right]}{9\left[k_{i}(1+\beta)+1\right]^{4}} \leq 0,
$$

while global optimality requires the Hessian matrix to be semi-definite negative, i.e.:

$$
\Delta H=\left(\frac{\partial^{2} \pi_{i}}{\partial k_{i}^{2}}\right)^{2}-\left(\frac{\partial^{2} \pi_{i}}{\partial k_{i} \partial k_{j}}\right)^{2} \geq 0
$$

where

$$
\begin{aligned}
\Delta H & =\frac{4 \bar{c}^{2}(2-\beta)\left(1-\beta^{2}\right)\left[2 a\left(k_{i}(1+\beta)+1\right)-3 \bar{c}\right] \Gamma}{81\left[k_{i}(1+\beta)+1\right]^{8}} \\
\Gamma & \equiv 2 a(2+\beta)\left(k_{i}(1+\beta)+1\right)-\bar{c}(10-\beta) .
\end{aligned}
$$

Using $k_{i}=k^{N}$ we can verify numerically that conditions (a1) and (a2) are met for all $\beta \in[0,1]$.

Unlike previous research on the same topic, the present model features no kinks in the SOCs. One may prove this by normalising $a-\bar{c}=1$ and plotting the SOCs over $r, \beta \in[0,1]$. This is the outcome of the functional form adopted to describe the R\&D technology that belongs to the unit interval. 


\section{References}

[1] Amir, R. (2000), "Modelling Imperfectly Appropriable R\&D Via Spillovers", International Journal of Industrial Organization, 18, 101332.

[2] Amir, R. and J. Wooders (1998), "Cooperation vs Competition in R\&D: The Role of Stability of Equilibrium", Journal of Economics, 67, 63-73.

[3] Amir, R. and J. Wooders (2003), "Noncooperative versus Cooperative R\&D with Endogenous Spillover Rates", Games and Economic Behavior, 42, 183-207.

[4] Cellini, R. and L. Lambertini (2003), "Dynamic R\&D with Spillovers: Competition vs Cooperation", Working paper no. 495, Department of Economics, University of Bologna.

[5] d'Aspremont, C. and A. Jacquemin (1988), "Cooperative and Noncooperative R\&D in Duopoly with Spillovers", American Economic Review, 78, 1133-37.

[6] d'Aspremont, C. and A. Jacquemin (1990), "Erratum", American Economic Review, 80, 641-2.

[7] EC Commission (1990), Competition Law in the European Communities, Volume I, Rules Applicable to Undertakings, Brussels-Luxembourg, EC Commission.

[8] Goto, A. and R. Wakasugi (1988), "Technology Policy", in Komiya, R., M. Okuno and K. Suzumura (eds.), Industrial Policy of Japan, New York, Academic Press. 
[9] Henriques, I. (1990), "Cooperative and Noncooperative R\&D with Spillovers: Comment", American Economic Review, 80, 638-40.

[10] Jaffe, A. B. (1986), "Technological Opportunity and Spillovers of R\&D: Evidence from Firms' Patents, Profits, and Market Value", American Economic Review, 76, 984-1001.

[11] Kamien, M.I., E. Muller and I. Zang (1992), "Cooperative Joint Ventures and R\&D Cartels", American Economic Review, 82, 1293-1306.

[12] Katsoulacos, Y. and D. Ulph (1998), "Endogenous Spillovers and the Performance of Research Joint Ventures", Journal of Industrial Economics, 46, 333-57.

[13] Katz, M.L. (1986), "An Analysis of Cooperative Research and Development", RAND Journal of Economics, 17, 527-43.

[14] Katz, M. and J. Ordover (1990), "R\&D Cooperation and Competition", Brookings Papers, Microeconomics, 137-203.

[15] Suzumura, K. (1992), "Cooperative and Noncooperative R\&D in Duopoly with Spillovers", American Economics Review, 82, 1307-20. 